This is the final peer-reviewed accepted manuscript of:

C. Biserni, F.L. Dalpiaz, T.M. Fagundes, M. Garai, L.A.O. Rocha, Geometric optimization of morphing fins coupled with a semicircular heat generating body: $A$ numerical investigation on the basis of Bejan's theory, International Communications in Heat and Mass Transfer, Volume 86, 2017, Pages 81-91, ISSN 0735-1933

The final published version is available online at:

https://doi.org/10.1016/i.icheatmasstransfer.2017.05.006

Rights / License:

The terms and conditions for the reuse of this version of the manuscript are specified in the publishing policy. For all terms of use and more information see the publisher's website.

This item was downloaded from IRIS Università di Bologna (https://cris.unibo.it/)

When citing, please refer to the published version. 


\title{
GEOMETRIC OPTIMIZATION OF MORPHING FINS COUPLED WITH A SEMICIRCULAR HEAT GENERATING BODY: A NUMERICAL INVESTIGATION ON THE BASIS OF BEJAN'S THEORY
}

\author{
C. Biserni ${ }^{1}$, F. L. Dalpiaz ${ }^{2}$, T. M. Fagundes ${ }^{2}$, M. Garai ${ }^{1}$ and L. A. O. Rocha ${ }^{3}$ \\ ${ }^{1}$ Dipartimento di Ingegneria Industriale, Università degli Studi di Bologna, Viale \\ Risorgimento 2, 40136 Bologna, Italy. \\ ${ }^{2}$ Universidade Federal do Rio Grande do Sul, Programa de Pós-Graduação em Engenharia \\ Mecânica, Rua Sarmento Leite, 425, 90050-170 - Porto Alegre, RS, Brazil. \\ ${ }^{3}$ Department of Mechanical Engineering, Universidade Federal do Rio Grande do Sul, Rua \\ Sarmento Leite, 425, Porto Alegre, RS, 90.050-170, Brazil.
}

\begin{abstract}
The objective of the present work is to optimize, by means of constructal design associated with exhaustive search and genetic algorithm, the geometry of morphing Tshaped fins that remove heat from a semicircular basement. The fins are bathed by a steady stream with constant ambient temperature and convective heat transfer. The semicircular body that serves as a basement for the T-shaped construct generates heat uniformly and it is perfectly insulated on the outer perimeter. It is shown numerically that the global thermal resistance can be minimized by geometric optimization subjected to constraints, namely, the basement area constraint, the T-shaped fins area fraction constraint and the auxiliary area fraction constraint, i.e. the ratio between the area that circumscribes the T-shaped fin and the basement area. The combination of the degrees of freedom values in the context of constructal design generated a search space with several "potential" local minima so that the classic technique, i.e. the exhaustive search, had to be substituted by the genetic algorithm method. In this context, the initial investigation regarding the degrees of freedom $L_{1} / L_{0}$ and $t_{1} / t_{0}$ was performed by means of the exhaustive search, while the parameters $k_{p}, \phi$, $\lambda$ and $\psi$ have been studied by employing GA technique. First achieved results indicate that when the geometry is free to morph then the thermal performance is improved according to the constructal principle named by Bejan "optimal distribution of imperfections". Finally, a
\end{abstract}


comparative analysis between T-shaped constructs coupled with rectangular, trapezoidal and semicircular geometries has been carried out in terms of effectiveness in heat removal. The performance of the T-shaped morphing fin having semicircual basement (the case here treated) prooved to be considerably superior than the other tested geometries.

Keywords: Constructal design, semicircular heat generating body, T-shaped morphing fins, thermal energy removal, convection heat transfer, exhaustive search, genetic algorithm

\author{
Nomenclature \\ $\mathrm{A}_{\mathrm{b}} \quad$ cross section area $\left[\mathrm{m}^{2}\right]$ \\ $\mathrm{h} \quad$ heat transfer coefficient $\left[\mathrm{W} \mathrm{m} \mathrm{m}^{-2} \mathrm{~K}^{-1}\right]$ \\ $\mathrm{k}_{\mathrm{b}} \quad$ basement thermal conductivity $\left[\mathrm{W} \mathrm{m}^{-1} \mathrm{~K}^{-1}\right]$ \\ $\mathrm{k}_{\mathrm{f}} \quad$ fin thermal conductivity $\left[\mathrm{W} \mathrm{m} \mathrm{m}^{-1} \mathrm{~K}^{-1}\right.$ ] \\ $\mathrm{L}_{0} \quad$ stem length $[\mathrm{m}]$ \\ $\mathrm{L}_{1} \quad$ half length of the tributary $[\mathrm{m}]$ \\ q" ' heat uniformly at volumetric rate $\left[\mathrm{W} \mathrm{m}^{-3}\right]$ \\ $\mathrm{R}$ radius of the semicircular basement [m] \\ $\mathrm{t}_{0} \quad$ stem thickness [m] \\ $\mathrm{t}_{1} \quad$ tributary thickness $[\mathrm{m}]$ \\ $\mathrm{T}$ temperature $[\mathrm{K}]$ \\ $\mathrm{T}_{\infty} \quad$ bulk temperature $[\mathrm{K}]$ \\ W width [m] \\ $\mathrm{x}, \mathrm{y}$ coordinates $[\mathrm{m}]$
}

\title{
Greek symbols
}

$\phi \quad$ area fraction

$\theta \quad$ dimensionless temperature

$\lambda$ dimensionless parameter

$\psi \quad$ auxiliary area fraction 


\section{Subscripts \\ b basement \\ aux auxiliary \\ $\mathrm{m} \quad$ once minimized \\ $2 \mathrm{~m} \quad$ twice minimized \\ $\max$ maximum \\ o optimized \\ 2o twice optimized}

\section{Superscripts}

( ) dimensionless variables

\section{Introduction}

Constructal Theory, i.e. the view of design as science, has been deeply reviewed in Refs. [1-3]. It is based on the Constructal Law, that states "For a finite-size flow system to persist in time (to live), its configuration must evolve in such a way that provides greater and greater access to the currents that flow through it'. This line of inquiry began accidentally in engineering, with a 1997 analytical paper on the conductive cooling of a small electronic package (a heat generating volume) by using a point-size heat sink [4]. Constructal theory $[5,6]$ can be intended as the evolutionary design philosophy for developing flow architectures that offer greater flow access and system performance. Therefore, a great distinction has been set between the approach by fractals [7-9] and by the Constructal Theory [10]. While the former produces images with great resemblance of natural systems it does not rely on physics. The latter, on the other hand, claims that forms, patterns and configurations can be successfully determined and explained by physics [11]. Literature [12] shows that Contructal Law provides explanations for why a broader variety of designs, configurations, structures, patterns and rithms occurred in the natural and in the anthropic realms alike. References $[13,14]$ illustrate that the most basic features of tree and forest architecture can be put on a unifying theoretical basis given by the constructal 
law. Trees and forests are viewed as integral components (along with river basins, atmospheric and oceanic circulation, etc.) of the much greater global architecture that facilitates the cyclical flow of water and the flow of stresses between wind and ground. Ref. [15] highlighted the oneness of animate and inanimate designs, the origin of finite-size organs on animals and vehicles, the flow of stresses as the generator of design in solid structures (skeletons, vegetation), the universality and rigidity of hierarchy in all flow systems, and the global design of human flows. Ref. [16] illustrates a model of heat transport on the earth surface that accounts for the solar and terrestrial radiation as the heat source and heat sink and with natural convection loops as the transport mechanism. In this paper we consider the constructal theory in its original engineering focus, i.e. the geometric optimization of shapes in heat transfer. In this context, Bejan's Constructal theory has been widely adopted in heat transfer optimization. Ref. [17] illustrates the constructal optimizations of $\mathrm{H}$ - and $\mathrm{X}$-shaped heat exchangers by taking the maximum thermal efficiency (the ratio of the dimensionless heat transfer rate to the dimensionless total pumping power) as optimization objective. The advantage of constructal law in the engineering field is that the flow architecture is not assumed in advance, but it is the consequence of allowing the structure to morph [18-21]. Several applications of constructal theory have been reviewed by Feng et al. in Ref. [22].

In this paper our focus is on the geometric study of T-shaped fins cooling a semicircular solid body with internal heat generation. The objective is to minimize, by means of the numerical investigation, the maximal excess of temperature between the solid body and the ambient. The fins are bathed by a steady stream with constant ambient temperature and convective heat transfer. The outer surfaces of the heat generating body are perfectly insulated.

\section{Mathematical model}

Consider the domain shown in Fig. 1. There is an adiabatic semicircular body (basement) with internal constant heat generation per unit volume $q$ ", and constant thermal conductivity $k_{b}$. Attached to the body is a T-shaped fin. The configuration is two- 
dimensional, with the third dimension $(W)$ sufficiently long in comparison with the body radius $R$. The heat transfer coefficient $h$ is uniform over all the exposed surfaces of the Tshaped fins and the temperature of the fluid $\left(T_{\infty}\right)$ is known. The maximum temperature $\left(T_{\max }\right)$ occurs into the basement and varies with the geometry of the T-shaped construct.

The objective of the analysis is to determine the optimal geometry $\left(L_{1} / L_{0}, t_{1} / t_{0}\right)$, that is characterized by the maximal excess of temperature $\left(T_{\max }-T_{\infty}\right) /\left(q,{ }^{\prime \prime} A_{b} / k_{b}\right)$. According to constructal design, this search can be subjected to constraints, namely, the cross section area, $\mathrm{A}_{\mathrm{b}}$, of the rectangular body constraint,

$$
A_{b}=\frac{1}{2} \pi R^{2}
$$

where $\mathrm{R}$ is the radius of the semicircular basement. The T-shaped fin-material area constraint,

$$
A_{f}=t_{0} L_{0}+2 t_{1} L_{1}
$$

The area that circumscribes one T-shaped fins is given by

$$
A_{\text {aux }}=2 L_{0} L_{l} .
$$

Equations (2) and (3) can be expressed respectively as the T-shaped fins area fraction

$$
\phi=\frac{A_{f}}{A_{b}}
$$

and area fraction constraint given by the ratio between the area that circumscribes the Tshaped fins and the basement area:

$$
\psi=\frac{A_{a u x}}{A_{b}}
$$

The analysis that delivers the maximal excess of temperature as a function of the T-shaped geometry consists to solve numerically the heat conduction equation along the entire domain. The basement body is governed by the steady heat conduction equation with heat generation 


$$
\frac{\partial^{2} \theta}{\partial \tilde{x}^{2}}+\frac{\partial^{2} \theta}{\partial \tilde{y}^{2}}+1=0
$$

while the steady heat conduction equation without generation is applied in the T-shaped fin territory:

$$
\frac{\partial^{2} \theta}{\partial \tilde{x}^{2}}+\frac{\partial^{2} \theta}{\partial \tilde{y}^{2}}=0
$$

where the dimensionless variables are

$$
\begin{gathered}
\theta=\frac{T-T_{\infty}}{q^{\prime \prime \prime} A_{b} / k_{b}} \\
\left(\tilde{x}, \tilde{y}, \tilde{L}_{0}, \tilde{L}_{1}, \tilde{t}_{0}, \tilde{t_{1}}, \tilde{R},\right)=\frac{\left(x, y, L_{0}, L_{1}, t_{0}, t_{1}, R\right)}{A_{b}{ }^{1 / 2}}
\end{gathered}
$$

and

$$
k_{p}=\frac{k_{f}}{k_{b}}
$$

The outer surfaces of the basement body are insulated and the boundary conditions are given by:

$$
\frac{\partial \theta}{\partial \tilde{n}}=0
$$

while the boundary conditions on the fin surfaces are:

$$
-\frac{\partial \theta}{\partial \tilde{y}}=\lambda \theta \quad \text { or } \quad-\frac{\partial \theta}{\partial \tilde{x}}=\lambda \theta
$$

where the parameter $\lambda$, according to Ref. [23], is defined as follows:

$$
\lambda=\frac{h A_{b}^{1 / 2}}{k_{f}}
$$

The dimensionless form of equations (1) and (4) and (5) are 


$$
\begin{array}{r}
1=\frac{1}{2} \pi \tilde{R}^{2} \\
\phi=2 \tilde{L}_{1} \tilde{t}_{1}+\tilde{L}_{0} \tilde{t}_{0} \\
\psi=2 \tilde{L}_{0} \tilde{L}_{1}
\end{array}
$$

The maximal excess of temperature, $\theta_{\text {max }}$, according to equation (8) is given by

$$
\theta_{\max }=\frac{T_{\max }-T_{\infty}}{q^{\prime \prime \prime} A_{b} / k_{b}}
$$

\section{Exhaustive Search: Numerical Model and Optimal Geometry}

The heat conduction equations for the basement with internal heat generation and for the T-shaped fin, given respectively by eqs. (6) and (7), can be solved numerically with the purpose to determine the function defined by eq. (17). In this context, eqs. (6) and (7) were solved using a finite elements code based on triangular elements, developed in MATLAB environment, more precisely the PDE (partial-differential-equations) toolbox [24]. The grid was non-uniform in both $\tilde{x}$ e $\tilde{y}$ directions and varied from one geometry to the next. The appropriate mesh size was determined by successive refinements, increasing the number of elements four times from the current mesh size to the next mesh size, until the criterion $\left|\left(\theta_{\max }^{j}-\theta_{\max }^{j+1}\right) / \theta_{\max }^{j}\right|<3.5 \times 10^{-3}$ was satisfied. Here $\theta_{\max }^{j}$ represents the maximum

temperature calculated using the current mesh size, and $\theta_{\max }^{j+1}$ corresponds to the maximum temperature using the next mesh, where the number of elements was increased by four times. Table 1 gives an example of how grid independence was achieved. 


\begin{tabular}{ccc}
\hline Number of Elements & $\theta_{\max }^{j}$ & $\left|\left(\theta_{\max }^{j}-\theta_{\max }^{j+1}\right) / \theta_{\max }^{j}\right|$ \\
\hline 994 & 0.5423 & $2.67 \mathrm{E}-02$ \\
3976 & 0.5572 & $1.36 \mathrm{E}-02$ \\
15904 & 0.5649 & $6.90 \mathrm{E}-03$ \\
$\mathbf{6 3 6 1 6}$ & $\mathbf{0 . 5 6 8 8}$ & $\mathbf{3 . 4 8} \mathbf{E}-\mathbf{0 3}$ \\
254464 & 0.5708 &
\end{tabular}

Table 1. Numerical tests showing the achievement of grid independence $\left(\phi=0.3, \mathrm{k}_{\mathrm{p}}=200\right.$, $\psi=1, \lambda=0.5)$.

The numerical work consisted of determining the temperature field in a large number of configurations of the type shown in Fig. 1. Figure 2 exhibits the effect of $L_{1} / L_{0}$ on the maximum excess of temperature , $\theta_{\max }$, for several values of the ratio $t_{1} / t_{0}$ (i.e. the second degree of freedom) when the parameters $\phi, \psi, \lambda, k_{p}$ are fixed $\left(\phi=0.3, \psi=1, \lambda=0.5, k_{p}\right.$ $=200$ ). For every value of $t_{1} / t_{0}$ investigated, there is an intermediate value of $L_{1} / L_{0}$ which minimizes $\theta_{\max }$. The results of Fig. 2 have been summarized in Fig. 3. The once minimized maximum excess of temperature $\left(\theta_{\max }\right)_{\mathrm{m}}$ and the once optimized ratio $\left(L_{1} / L_{0}\right)_{0}$ are highlighted as function of the ratio $t_{1} / t_{0}$. Based on pure observation, $\left(\theta_{\max }\right)_{\mathrm{m}}$ is practically insensitive to the variation of the ratio $t_{1} / t_{0}$ while $\left(L_{l} / L_{0}\right)_{o}$ decreases monotonically with $t_{1} / t_{0}$. Some of the shapes investigated in Fig. 3 are plotted in scale in Fig. 4 highlighting the temperature field.

\section{Genetic Algorithm for Design Optimization}

The combination of degrees of freedom values generated a search space with several local minima: the search for optimal shapes by means of the classic technique, called exhaustive search (described on paragraph 3), had to be continued by the employment of Genetic Algorithm (GA). The reason is that the exhaustive method with the evaluation of all cases of the problem domain is computationally expensive, not allowing the geometric optimization of numerous degrees of freedom and parameters. On the contrary, the GA 
method is recommended for multivariable problems in which systems with complex architectures are involved according to constructal design. Thus, with reference to the case here treated, the initial investigation regarding the degrees of freedom $L_{1} / L_{0}$ and $t_{1} / t_{0}$ was performed by means of the exhaustive search (see paragraph 3) while the parameters $k_{p}, \phi$, $\lambda$ and $\psi$ have been studied in this section by employing GA technique. The GA begins with the definition of three basic components [25]: (i) the input variables, i.e. chromosomes or elements of population, represented by continuous or discrete values; (ii) the cost function used to evaluate the cost of each element of the population (it may be an algebraic function, an experiment or a simulation) and (iii) the cost: value returned by the cost function for each element of population. In this work, the degrees of freedom, the simulation and the dimensionless maximum excess of temperature $\left(\theta_{\max }\right)$ correspond to each of these components, respectively. First, the parameters of the GA have to be introduced [26-28] (selection function, crossover rate, mutation rate and stopping conditions) as well as the number of degrees of freedoms used in the problem (input variables). The next step consists of generation of the initial population with a defined size, where each individual has a random value. Afterwards, the cost of each element of population is calculated by applying the cost function (numerical simulation). At this moment, there is an association between elements of the population (geometries) and costs (maximum temperatures). From this point, the GA operators are applied. Initially, based on costs, a portion of the population (parents) is selected to be combined and to generate individuals (children) for the next generation. These steps are called selection and crossover. The next operator applied to create new individuals is the mutation, where new traits are introduced in the next generation, except on elite individuals. To summarize, GA convergence is verified by analysing the stop criterion. If the above mentioned stopping criteria are checked, the algorithm ends, otherwise, a new generation is created. The parameters used for the genetic algorithm calibration are shown in Table 2, next: 
Table 2. Genetic algorithm parameters

\begin{tabular}{cc}
\hline Parameter & Value \\
\hline Population size & 40 \\
Creation function & Uniform \\
Crossover function & Scattered \\
Mutation fraction & $10 \%$ \\
Crossover fraction & $80 \%$ \\
Generations & 200 \\
Stall Limit & 20 generations \\
\hline
\end{tabular}

The numerical work continued, by means of GA, with the investigation of the effect of the parameter $\mathrm{k}_{\mathrm{p}}$ over the twice minimized maximum excess of temperature $\left(\theta_{\max }\right)_{2 m}$ and over the optimal shapes: $\left(L_{1} / L_{0}\right)_{2 o}$ and $\left(t_{1} / t_{0}\right)_{o}$. Figure 5 illustrates graphically that $\left(\theta_{\max }\right)_{2 m}$ decreases weakly as $k_{p}$ increases (no local minimum in the curve can be detected): the optimal shape for heat removal has to be found in correspondence to the upper bound of the tested domain. This observation is also confirmed in Fig. 6 where some of the topologies obtained in Fig. 5 are highlighted. It is worth to mention that $\left(t_{1} / t_{0}\right)_{\mathrm{o}}$ is insensitive to the variation of $k_{p}$ while $\left(L_{1} / L_{0}\right)_{2 o}$ increases monotonically with $k_{p}$. The same procedure is now applied in Fig. 7 for several values of the volume fraction $\phi$ while the parameters $\psi, \lambda$ and $k_{p}$ are fixed $\left(\psi=1, \lambda=0.5\right.$ and $\left.k_{p}=200\right)$. Based on pure observation, even in this optimization procedure $\left(\theta_{\max }\right)_{2 m}$ decreases monotonically as $\phi$ increases. In the superior limit of the domain, for $\phi=1,\left(L_{1} / L_{0}\right)_{2 o}$ becomes equal to 27.4: the T-shaped construct performs better, $\left(\theta_{\max }\right)_{2 m}=0.3108$, when the stem is robust and the tributary slender. Fig. 8 highlights the temperature field in some of the configuration tested in Fig.7.

Afterwards, the influence of the parameter $\lambda$ is taken into account. It is worth mentioning that the range of variation of the parameter $\lambda$ here tested is wide: the minimal value here considered $\left(\lambda=10^{-4}\right)$ is one order of magnitude inferior than the one suggested by Bejan et al. [23] in the case of a common forced convection of gas flow with $\mathrm{h} \sim 10^{2} \mathrm{~W} /\left(\mathrm{m}^{2} \mathrm{~K}\right)$ over fin surfaces of aluminum and copper with a conductivity of $\mathrm{k} \sim 10^{2} \mathrm{~W} /(\mathrm{mK})$ and considering a length scale $\mathrm{A}^{1 / 2} \sim 1 \mathrm{~cm}$. In Fig. 9 the effect of $\lambda$ over the twice minimized maximum excess of temperature $\left(\theta_{\max }\right)_{2 m}$ has been produced with their respective optimal shapes: $\left(L_{1} / L_{0}\right)_{2 o}$ and $\left(t_{1} / t_{0}\right)_{o}$. The results show that $\left(\theta_{\max }\right)_{2 m}$ decreases monotonically with 
the augmentation of $\lambda$. Concerning the optimal geometries, $\left(L_{1} / L_{0}\right)_{o}$ presents a minimum and a maximum respectively in the vicinity of $\lambda=3 \times 10^{-4}$ and $\lambda=1.6 \times 10^{-2}$ while $\left(t_{1} / t_{0}\right)_{\mathrm{o}}$ is still insensitive to the variation of the tested parameter $(\lambda)$. Fig. 10 is dedicated to show in scale the geometry and temperature distribution of some configurations tested in Fig.9.

The final step of the present study consisted of a search for the best geometry varying the parameter $\psi$ : as expected, $\left(\theta_{\max }\right)_{2 m}$ increases as $\psi$ increases (see Fig.11). The augmentation of $\psi$ (with consequent increase of the auxiliary area) does not allow the system more freedom to morph, so that the best performance is reached in the inferior limit. Figure 12 shows some of the significant topologies found in Fig. 11. Figure 12(a) highlights the temperature distribution with reference to the inferior limit of the tested domain, previously mentioned, whose coordinates are: $\phi=0.3, \psi=0.05, \lambda=0.5, \mathrm{k}_{\mathrm{p}}=200,\left(\mathrm{t}_{1} / \mathrm{t}_{0}\right)_{\mathrm{o}}=0.1$, $\left(\mathrm{L}_{1} / \mathrm{L}_{0}\right)_{2 \mathrm{o}}=174.6$ and $\left(\theta_{\max }\right)_{2 \mathrm{~m}}=0.4011$.

\section{Concluding Remarks and Comparative Analysis}

This paper used constructal design in association with exhaustive search and genetic algorithm to optimize the complete geometry of convective T-shaped fins cooling a semicircular basement with internal heat generation whose outer surfaces are adiabatic. The objective is to minimize the maximal excess of temperature between the semicircular body and the ambient. Therefore, the initial investigation regarding the degrees of freedom $\mathrm{L}_{1} / \mathrm{L}_{0}$ and $t_{1} / t_{0}$ was performed by means of exhaustive search (see paragraph 3 ), while the parameters $k_{p}, \phi, \lambda$ and $\psi$ have been studied by employing GA technique (see paragraph 4 ). First, constructal design delivered the best shape: for every value of $t_{1} / t_{0}$ investigated, there is an intermediate value of $L_{1} / L_{0}$ which minimizes the maximum excess of temperature $\theta_{\max }$. Therefore, the variation of all the parameters was taken into account. Particular interest has to be ascribed to the study of the twice minimized maximum excess of temperature: $\left(\theta_{\max }\right)_{2 m}$ decreases weakly as $k_{p}$ increases (no local minimum in the curve can be detected) so that the optimal shape for heat removal has to be found in correspondence to the upper bound of the tested domain. Afterwards, the same procedure has been applied (see Fig. 7) for several values of the volume fraction $\phi$ while the parameters $\psi, \lambda$ and $k_{p}$ are 
fixed $\left(\psi=1, \lambda=0.5\right.$ and $\left.k_{p}=200\right)$. Even in this optimization procedure $\left(\theta_{\max }\right)_{2 m}$ decreases monotonically as $\phi$ increases. In the upper limit of the domain, for $\phi=1,\left(L_{1} / L_{0}\right)_{2 o}$ becomes equal to 27.4: the T-shaped construct performs better, $\left(\theta_{\max }\right)_{2 m}=0.3108$, when the stem is robust and the tributary slender. Finally, many ideas even regarding possible comparative studies emerged from this work: Figures 13(a), 13(b), 13(c) and 13(d) anticipate some results by considering the performance of rectangular, trapezoidal and semicircular heat generating bodies coupled with the same T-shaped fins. Figure 13(a) highlights the effect of the parameter $\mathrm{k}_{\mathrm{p}}$ over the maximum excess of temperature $\theta_{\max }$ while the influence of the area fraction $\phi$ and of auxilliary area fraction $\psi$ has been contemplated respectively in figure 13 (b) and 13(c). Similarly, Figure 13(d) shows the effect of the parameter $\lambda$ over the maximum excess of temperature $\theta_{\max }$. From visual observation, the T-shaped morphing fin for heat removal having semicircular basement (the case here treated) performs considerably better than the other tested geometries; the performance of the same cooling fin coupled with trapezoidal geometry is also superior than the rectangular one (the wost configuration). This assumption is confirmed in the following table, in which we notice how much (in percent) the trapezoidal geometry performs better than the rectangualar one (column 2) and how much in percent the semicircular geometry performs better than the trapezoidal one (column 3).

\begin{tabular}{ccc}
\hline$\lambda$ & $\begin{array}{c}\text { Performance of the } \\
\text { trapezoidal configuration } \\
\text { versus the rectangular } \\
\text { geometry }\end{array}$ & $\begin{array}{c}\text { Performance of the } \\
\text { semicircular configuration } \\
\text { versus the trapezoidal } \\
\text { geometry }\end{array}$ \\
\hline 0.001 & $20.8 \%$ & $1414.9 \%$ \\
0.1 & $15.9 \%$ & $331.1 \%$ \\
1 & $12.1 \%$ & $105.7 \%$ \\
3.5 & $31.0 \%$ & $68.2 \%$ \\
\hline
\end{tabular}

Table 3. Comparative analysis with reference to the heat transfer removal capability between semicircular, trapezoidal and rectangular configuration $\left(\phi=0.3, \mathrm{k}_{\mathrm{p}}=200, \psi=1\right)$. 
All the results here obtained emphasize that given a flow system freedom to morph, i.e. allowing changes in its degrees of freedom, it will improve the system performance in heat removal. This corroborates the constructal thinking that "freedom is good for design". As a consequence, all the best configurations proved to be the ones that distribute better the hot spots, according to the constructal principle of "optimal distributions of imperfections".

\section{Acknowledgements.}

Prof. Cesare Biserni and Prof. Massimo Garai were funded by the Italian Ministry for Education, University and Research. Prof. Luiz Rocha's work was sponsored by CNPq, Brasília, DF, Brazil.

\section{References}

[1] Rui N. Rosa, A. Heitor Reis, F. Miguel, Proceedings of the Symposium Bejan's Constructal Theory of Shape and Structure, Evora Geophysics Center, 2004.

[2] A. Bejan, Advanced Engineering Thermodynamics, third ed., Wiley, 2006.

[3] L.A.O. Rocha, S. Lorente, A. Bejan (Eds.), Constructal Law and the Unifying Principle of Design (Understanding Complex Systems), Springer, 2013.

[4] A. Bejan, Constructal-theory network of conducting paths for cooling a heat generating volume, Int. J. Heat Mass Transfer, 40, 799-816, 1997.

[5] A. Bejan, Shape and Structure, from Engineering to Nature, Cambridge University Press, 2000.

[6] A. Bejan and S. Lorente, Design with Constructal Theory, Wiley, Hoboken, 2008.

[7] P. Xu, B. Yu, M. Yun, M. Zou, Heat conduction in fractal tree-like branched networks, Int. J. Heat Mass Transfer, 49, 3746-3751, 2006.

[8] P.M. Bliss, D.A. Brown, Geometric properties of three-dimensional fractal trees, Chaos Solitons Fractals, 42, 119-124, 2009.

[9] D. Calamas, J. Baker, Tree-like branching fins: performance and natural convective heat transfer behavior, Int. J. Heat Mass Transfer, 62, 350-361, 2013.

[10] A. Bejan, The physics of life: the evolution of everything, St. Martin's Press, 2016. 
[11] M.R. Errera, A.L. Frigo, E.H.V. Segundo, The emergence of the constructal element in tree-shaped flow organization, Int. J. Heat Mass Transfer, 78, 181-188, 2014.

[12] A. Bejan, S. Lorente, Constructal law of design and evolution: physics, biology, technology, and society, J. Appl. Phys., 113, 1-20, 2013.

[13] A. Bejan, S. Lorente, L. Lee, Unifying constructal theory of tree roots, canopies and forests, J. Theor. Biol., 254, 529-540, 2008.

[14] A. Bejan, S. Lorente, Constructal Theory of Generation of Configuration in Nature and Engineering, J. Appl. Physics, 100, Article number 041301, 2006.

[15] A. Bejan, S. Lorente, The constructal law and the evolution of design in nature, Physics of Life Reviews, 8, 209-240, 2011.

[16] A. Heitor Reis, A. Bejan, Constructal theory of global circulation and climate, Int. J. Heat Mass Transfer, 49, 1857-1875, 2006.

[17] L. Chen, H. Feng, Z. Xie, F. Sun, Thermal efficiency maximization for H- and Xshaped heat exchangers based on constructal theory, Applied Thermal Eng., 91, 456-462, 2015.

[18] T. Bello-Ochende, L. Liebenberg, J.P. Meyer, Constructal cooling channels for microchannel heat sinks, Int. J. Heat Mass Transfer, 50, 4141-4150, 2007.

[19] T. Bello-Ochende, J.P. Meyer, A. Bejan, Constructal ducts with wrinkled entrances, Int. J. Heat Mass Transfer, 52, 3628-3633, 2009.

[20] O.T. Olakoyejo, T. Bello-Ochende, J.P. Meyer, Mathematical optimisation of laminar forced convection heat transfer through a vascularised solid with square channels, Int. J. Heat Mass Transfer, 55, 2402-2411, 2012.

[21] O.T. Olakoyejo, T. Bello-Ochende, J.P. Meyer, Constructal conjugate cooling channels with internal heat generation, Int. J. Heat Mass Transfer, 55, 4385-4396, 2012.

[22] H. Feng, L. Chen, Z. Xie, F. Sun, Constructal design for X-shaped hot water network over a rectangular area, Applied Thermal Eng., 87, 760-767, 2015.

[23] A.Bejan, M. Almogbel, Constructal T-shaped fins, Int. J. Heat Mass Transfer, 43, 2101-2115, 2000.

[24] MATLAB, User's guide, version 6.0.088 The Mathworks Inc., 2000. 
[25] G. Lorenzini, C. Biserni, E.D. Estrada, L.A. Isoldi,, E.D. dos Santos, L. A. O. Rocha, Constructal Design of Convective Y-Shaped Cavities by Means of Genetic Algorithm, J. Heat Tr., 136, 0717021- 07170210, 2014.

[26] J. H. Holland, Adaptation in Natural and Artificial Systems, University of Michigan Press, Ann Arbor, MI, 1975.

[27] D. E. Goldberg, Algorithms in Search, Optimization, and Machine Learning, AddisonWesley, Boston, MA, 1989.

[28] R. L. Haupt, S.E. Haupt, Practical Genetic Algorithms, John Wiley \& Sons, Hoboken, NJ, 1989.

\section{FIGURES}




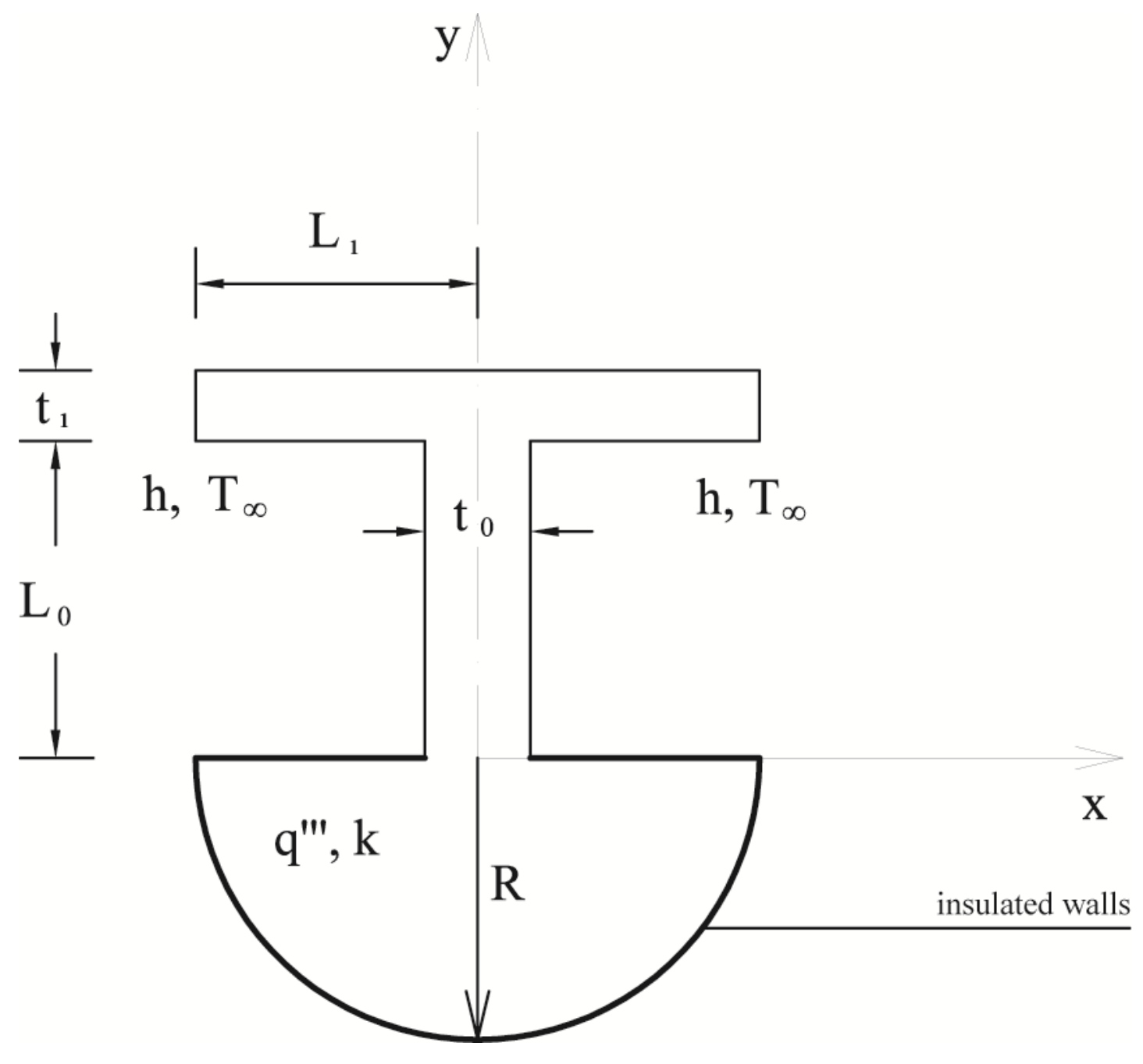

Figure 1 - Semicircular heat generating basement coupled with a morphing convective Tshaped fin. 


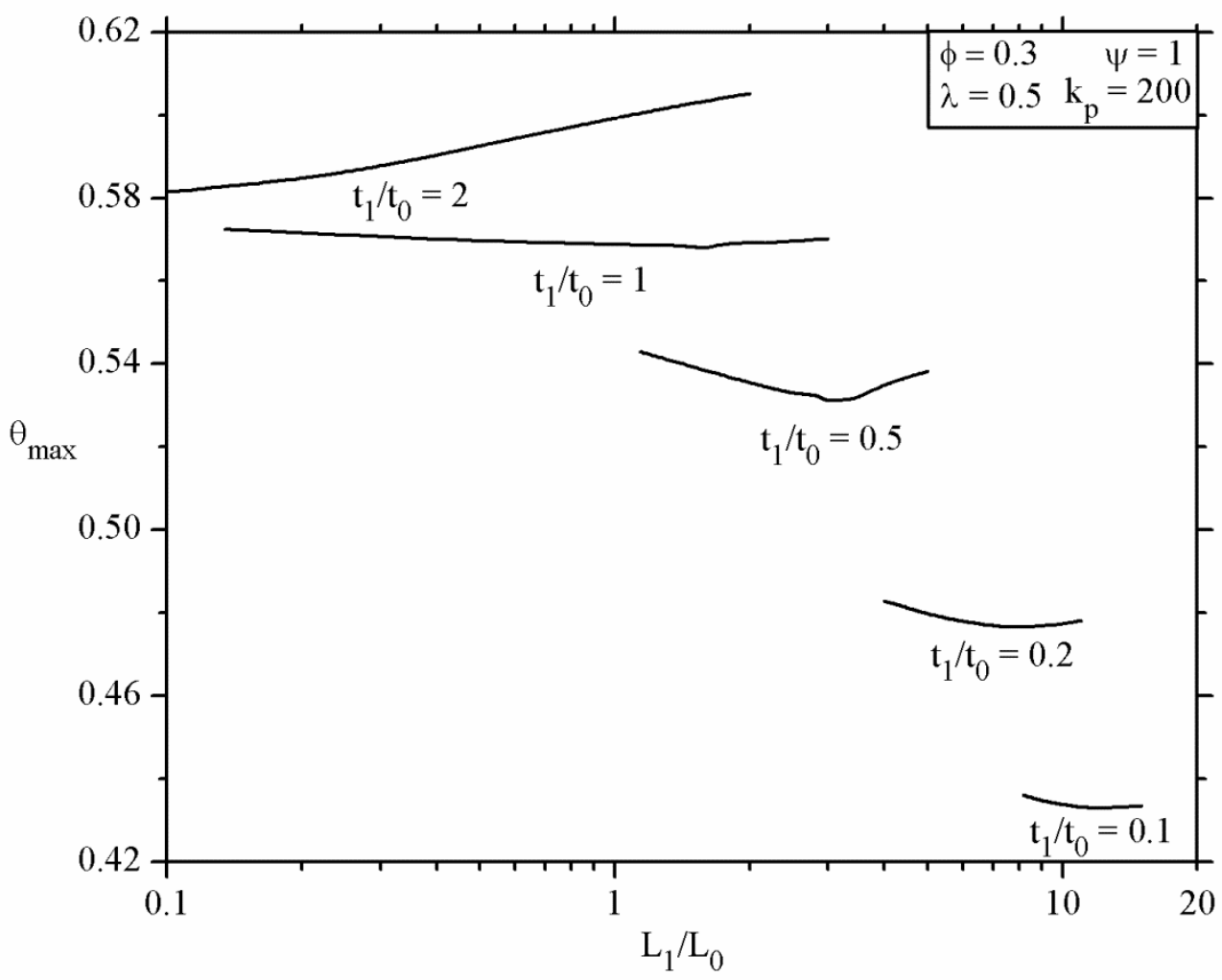

Figure 2 - Optimization of the maximum excess of temperature $\theta_{\max }$ as function of $\mathrm{L}_{1} / \mathrm{L}_{0}$ for several values of the ratio $t_{1} / t_{0}$. 


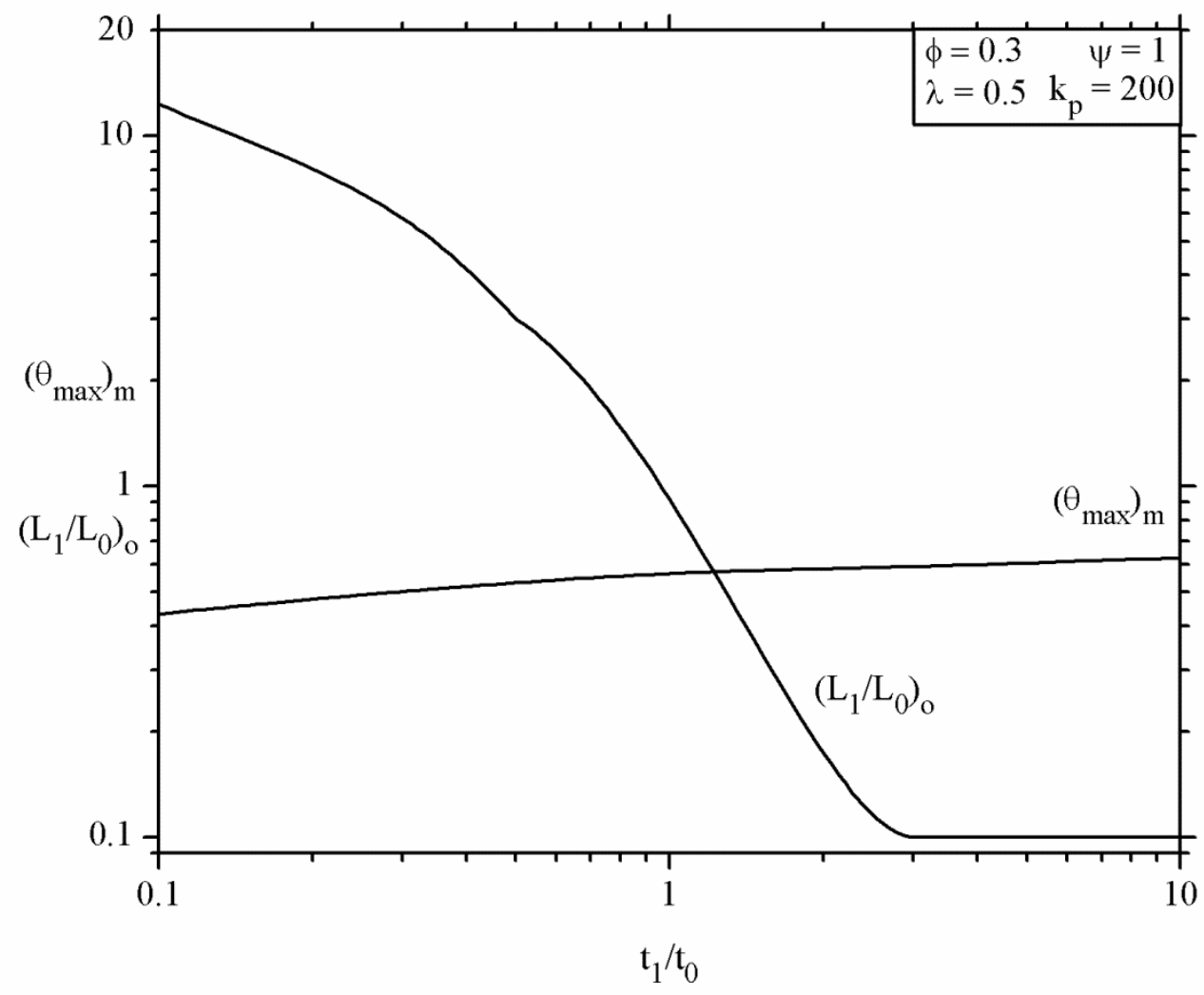

Figure 3 - The behavior of the once minimized maximum excess of temperature $\left(\theta_{\max }\right)_{\mathrm{m}}$ and the corresponding optimal ratio $\left(\mathrm{L}_{1} / \mathrm{L}_{0}\right)_{\mathrm{o}}$ as function of $\mathrm{t}_{1} / \mathrm{t}_{0}$. 


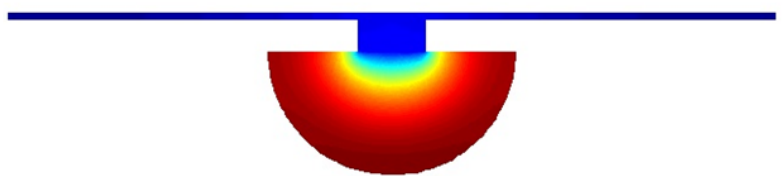

(a)

$$
\begin{gathered}
\phi=0.3 \quad \psi=1.0 \\
\lambda=0.5 \quad \mathrm{k}_{\mathrm{p}}=200 \\
\mathrm{t}_{1} / \mathrm{t}_{0}=0.1 \\
\left(\mathrm{~L}_{1} / \mathrm{L}_{0}\right)_{\mathrm{o}}=12.3 \\
\left(\theta_{\max }\right)_{\mathrm{m}}=0.4329
\end{gathered}
$$

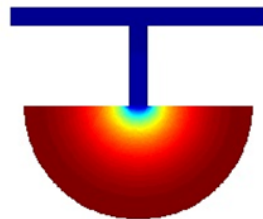

(b)

$$
\begin{gathered}
\phi=0.3 \quad \psi=1.0 \\
\lambda=0.5 \quad \mathrm{k}_{\mathrm{p}}=200 \\
\mathrm{t}_{1} / \mathrm{t}_{0}=1.0 \\
\left(\mathrm{~L}_{1} / \mathrm{L}_{0}\right)_{\mathrm{o}}=1.6 \\
\left(\theta_{\max }\right)_{\mathrm{m}}=0.5676
\end{gathered}
$$

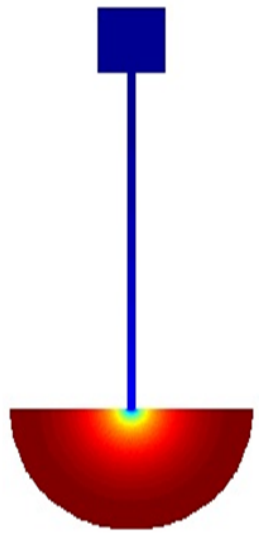

(c)

$\phi=0.3 \quad \psi=1.0$

$\lambda=0.5 \quad \mathrm{k}_{\mathrm{p}}=200$

$\mathrm{t}_{1} / \mathrm{t}_{0}=9.0$

$\left(\mathrm{L}_{1} / \mathrm{L}_{0}\right)_{\mathrm{o}}=0.1$

$\left(\theta_{\max }\right)_{\mathrm{m}}=0.6239$

Figure $4-$ The shapes of Fig. 3 as function of $\mathrm{t}_{1} / \mathrm{t}_{0}$. (a) $\phi=0.3, \psi=1, \lambda=0.5, \mathrm{k}_{\mathrm{p}}=200, t_{1} / t_{0}$ $=0.1,\left(\mathrm{~L}_{1} / \mathrm{L}_{0}\right)_{\mathrm{o}}=12.3$ and $\left(\theta_{\max }\right)_{\mathrm{m}}=0.4329$. (b) $\phi=0.3, \psi=1, \lambda=0.5, \mathrm{k}_{\mathrm{p}}=200, t_{1} / t_{0}=1$, $\left(\mathrm{L}_{1} / \mathrm{L}_{0}\right)_{\mathrm{o}}=1.6$ and $\left(\theta_{\max }\right)_{\mathrm{m}}=0.5676$. (c) $\phi=0.3, \psi=1, \lambda=0.5, \mathrm{k}_{\mathrm{p}}=200, t_{1} / t_{0}=9,\left(\mathrm{~L}_{1} / \mathrm{L}_{0}\right)_{\mathrm{o}}=$ 0.1 and $\left(\theta_{\max }\right)_{\mathrm{m}}=0.6239$. 


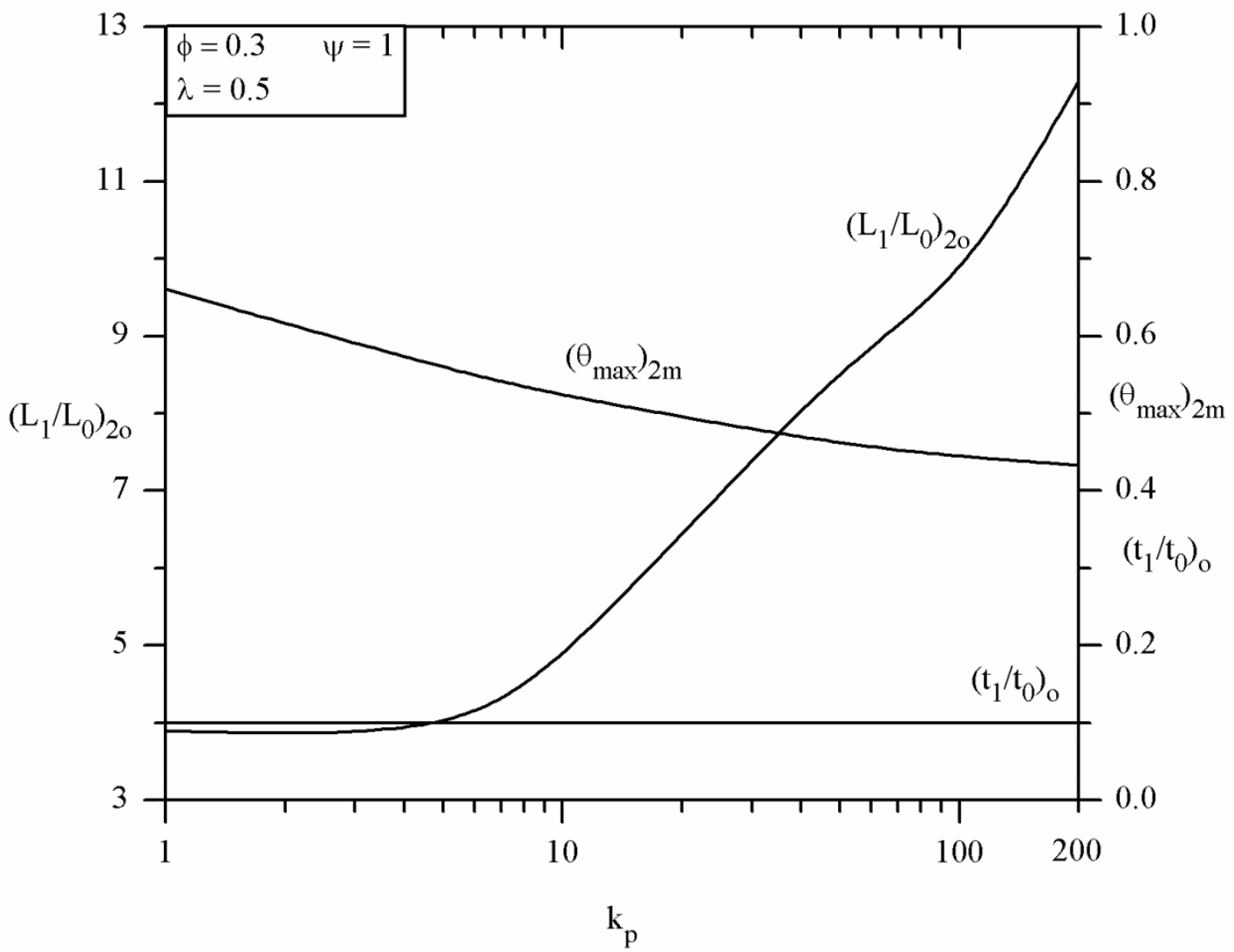

Figure 5 - Trend of the two times optimized $\left(\theta_{\max }\right)_{2 \mathrm{~m}},\left(\mathrm{~L}_{1} / \mathrm{L}_{0}\right)_{2 \mathrm{o}}$, and $\left(\mathrm{t}_{1} / \mathrm{t}_{0}\right)_{\mathrm{o}}$ as function of the parameter $\mathrm{k}_{\mathrm{p}}$. 


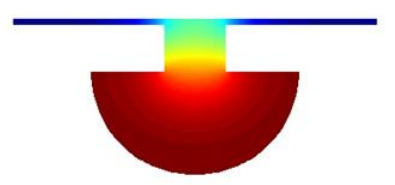

(a)

$\phi=0.3 \quad \psi=1.0$

$\lambda=0.5 \quad \mathrm{k}_{\mathrm{p}}=1$

$\left(\mathrm{t}_{1} / \mathrm{t}_{0}\right)_{\mathrm{o}}=0.1$

$\left(\mathrm{L}_{1} / \mathrm{L}_{0}\right)_{2 \mathrm{o}}=3.9$

$\left(\theta_{\max }\right)_{2 \mathrm{~m}}=0.6606$

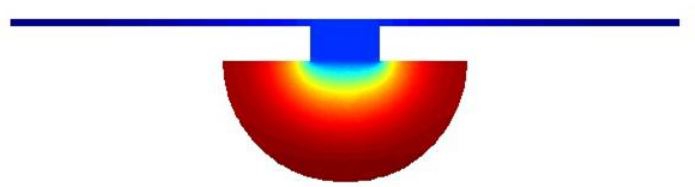

(c)

$$
\begin{gathered}
\phi=0.3 \quad \psi=1.0 \\
\lambda=0.5 \quad \mathrm{k}_{\mathrm{p}}=100 \\
\left(\mathrm{t}_{1} / \mathrm{t}_{0}\right)_{\mathrm{o}}=0.1 \\
\left(\mathrm{~L}_{1} / \mathrm{L}_{0}\right)_{2 \mathrm{o}}=9.6 \\
\left(\theta_{\max }\right)_{2 \mathrm{~m}}=0.4439
\end{gathered}
$$

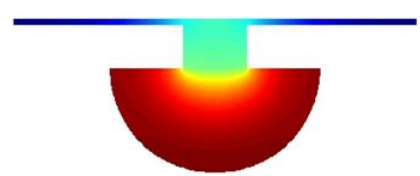

(b)

$\phi=0.3 \quad \psi=1.0$

$\lambda=0.5 \quad \mathrm{k}_{\mathrm{p}}=10$

$\left(\mathrm{t}_{1} / \mathrm{t}_{0}\right)_{\mathrm{o}}=0.1$

$\left(\mathrm{L}_{1} / \mathrm{L}_{0}\right)_{2 \mathrm{o}}=4.7$

$\left(\theta_{\max }\right)_{2 \mathrm{~m}}=0.5220$

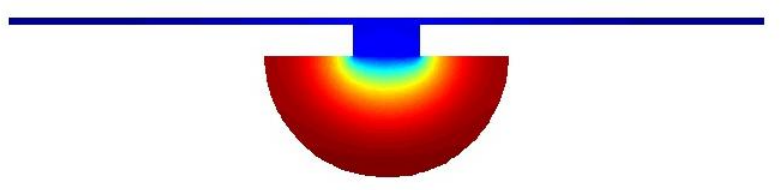

(d)

$\phi=0.3 \quad \psi=1.0$

$\lambda=0.5 \quad \mathrm{k}_{\mathrm{p}}=200$

$\left(\mathrm{t}_{1} / \mathrm{t}_{0}\right)_{\mathrm{o}}=0.1$

$\left(\mathrm{L}_{1} / \mathrm{L}_{0}\right)_{2 \mathrm{o}}=12.3$

$\left(\theta_{\max }\right)_{2 \mathrm{~m}}=0.4329$

Figure 6 - The shapes of Fig. 5 as function of $\mathrm{k}_{\mathrm{p}}$. (a) $\phi=0.3, \psi=1, \lambda=0.5, \mathrm{k}_{\mathrm{p}}=1,\left(\mathrm{t}_{1} / \mathrm{t}_{0}\right)_{\mathrm{o}}=$ $0.1,\left(\mathrm{~L}_{1} / \mathrm{L}_{0}\right)_{2 \mathrm{o}}=3.9$ and $\left(\theta_{\max }\right)_{2 \mathrm{~m}}=0.6606$. (b) $\phi=0.3, \psi=1, \lambda=0.5, \mathrm{k}_{\mathrm{p}}=10,\left(\mathrm{t}_{1} / \mathrm{t}_{0}\right)_{\mathrm{o}}=0.1$, $\left(\mathrm{L}_{1} / \mathrm{L}_{0}\right)_{2 \mathrm{o}}=4.7$ and $\left(\theta_{\max }\right)_{2 \mathrm{~m}}=0.5220$. (c) $\phi=0.3, \psi=1, \lambda=0.5, \mathrm{k}_{\mathrm{p}}=100,\left(\mathrm{t}_{1} / \mathrm{t}_{0}\right)_{\mathrm{o}}=0.1$, $\left(\mathrm{L}_{1} / \mathrm{L}_{0}\right)_{2 \mathrm{o}}=9.6$ and $\left(\theta_{\max }\right)_{2 \mathrm{~m}}=0.4439$. (d) $\phi=0.3, \psi=1, \lambda=0.5, \mathrm{k}_{\mathrm{p}}=200,\left(\mathrm{t}_{1} / \mathrm{t}_{0}\right)_{\mathrm{o}}=0.1$, $\left(\mathrm{L}_{1} / \mathrm{L}_{0}\right)_{2 \mathrm{o}}=12.3$ and $\left(\theta_{\max }\right)_{2 \mathrm{~m}}=0.4329$. 


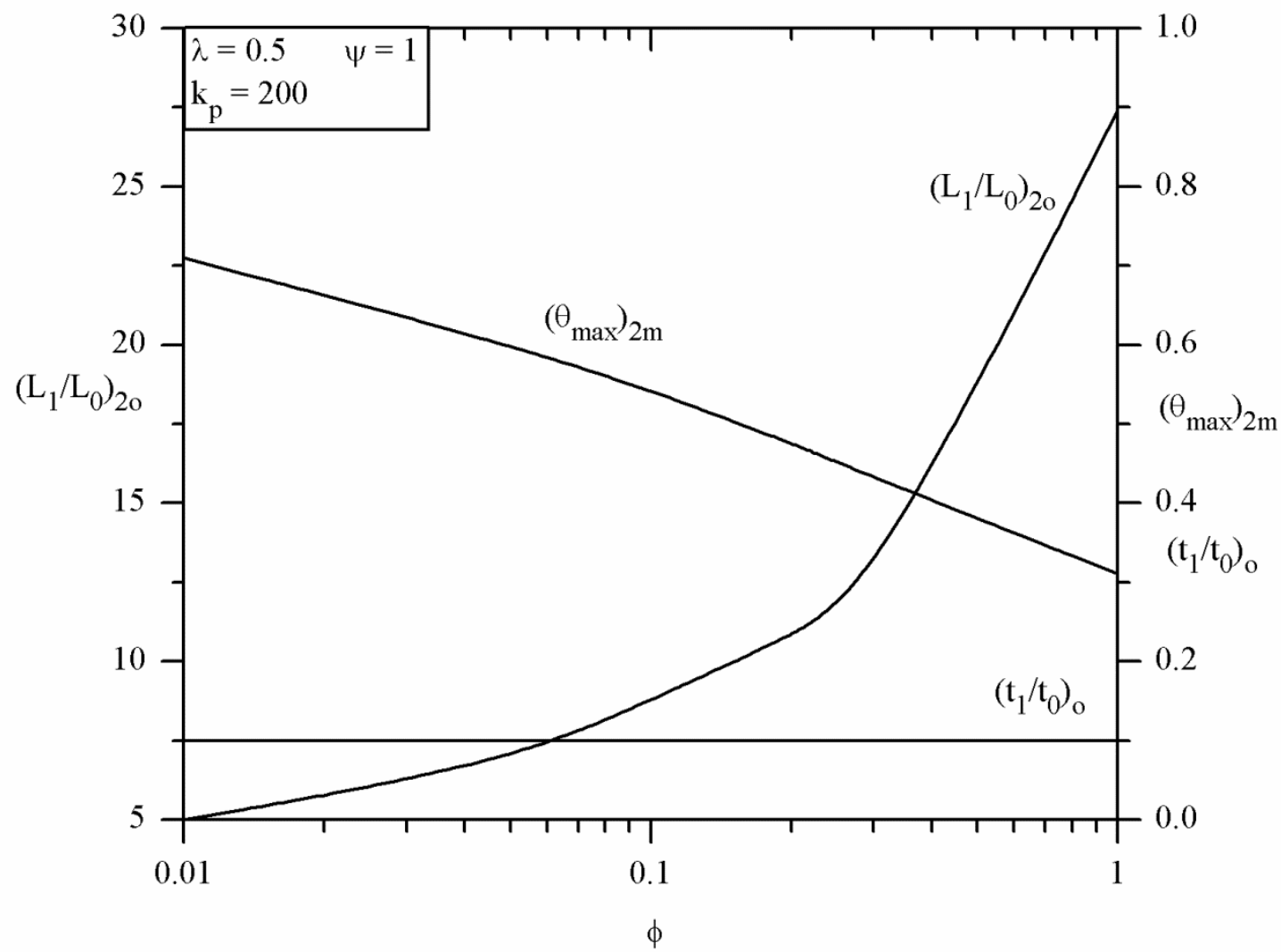

Figure 7 - The effect of the T-shaped fin area fraction $\phi$ over the twice minimized maximum excess of temperature $\left(\theta_{\max }\right)_{2 \mathrm{~m}}$ and the corresponding optimal shapes $\left(\mathrm{L}_{1} / \mathrm{L}_{0}\right)_{20}$ and $\left(\mathrm{t}_{1} / \mathrm{t}_{0}\right)_{\mathrm{o}}$. 


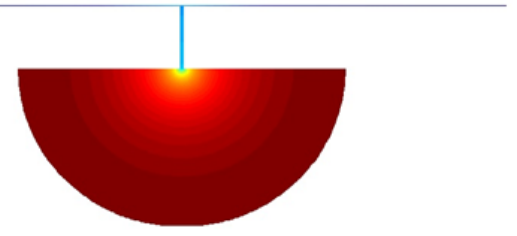

(a)

$\phi=0.01 \quad \psi=1.0$

$\lambda=0.5 \quad \mathrm{k}_{\mathrm{p}}=200$

$\left(\mathrm{t}_{1} / \mathrm{t}_{0}\right)_{\mathrm{o}}=0.1$

$\left(\mathrm{L}_{1} / \mathrm{L}_{0}\right)_{2 \mathrm{o}}=5.0$

$\left(\theta_{\max }\right)_{2 \mathrm{~m}}=0.7099$

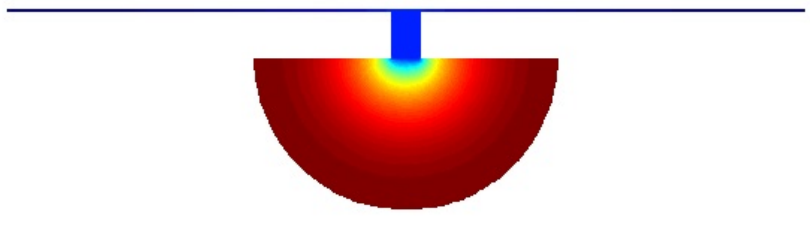

(b)

$\phi=0.10 \quad \psi=1.0$

$\lambda=0.5 \quad \mathrm{k}_{\mathrm{p}}=200$

$\left(\mathrm{t}_{1} / \mathrm{t}_{0}\right)_{\mathrm{o}}=0.1$

$\left(\mathrm{L}_{1} / \mathrm{L}_{0}\right)_{2 \mathrm{o}}=8.8$

$\left(\theta_{\max }\right)_{2 \mathrm{~m}}=0.5429$

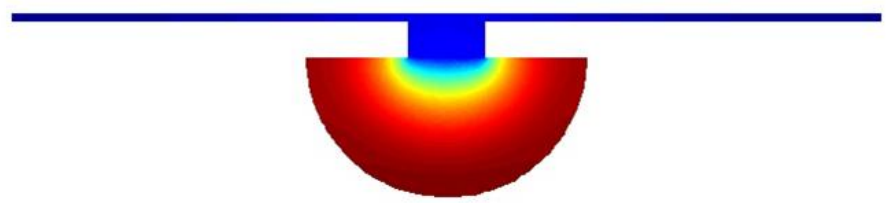

(c)

$\phi=0.30 \quad \psi=1.0$

$\lambda=0.5 \quad \mathrm{k}_{\mathrm{p}}=200$

$\left(\mathrm{t}_{1} / \mathrm{t}_{0}\right)_{\mathrm{o}}=0.1$

$\left(\mathrm{L}_{1} / \mathrm{L}_{0}\right)_{2 \mathrm{o}}=12.3$

$\left(\theta_{\max }\right)_{2 \mathrm{~m}}=0.4329$

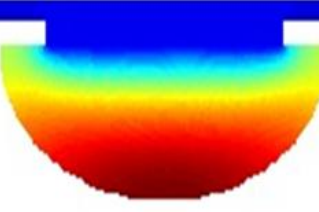

(d)

$$
\begin{gathered}
\phi=1.00 \quad \psi=1.0 \\
\lambda=0.5 \quad \mathrm{k}_{\mathrm{p}}=200 \\
\left(\mathrm{t}_{1} / \mathrm{t}_{0}\right)_{\mathrm{o}}=0.1 \\
\left(\mathrm{~L}_{1} / \mathrm{L}_{0}\right)_{2 \mathrm{o}}=27.4 \\
\left(\theta_{\max }\right)_{2 \mathrm{~m}}=0.3108
\end{gathered}
$$

Figure 8 - The optimal shape of Fig. 7 as function of $\phi$. (a) $\phi=0.01, \psi=1, \lambda=0.5, \mathrm{k}_{\mathrm{p}}=$ $200,\left(\mathrm{t}_{1} / \mathrm{t}_{0}\right)_{\mathrm{o}}=0.1,\left(\mathrm{~L}_{1} / \mathrm{L}_{0}\right)_{2 \mathrm{o}}=5$ and $\left(\theta_{\max }\right)_{2 \mathrm{~m}}=0.7099$. (b) $\phi=0.1, \psi=1, \lambda=0.5, \mathrm{k}_{\mathrm{p}}=200$,

$$
\begin{gathered}
\left(\mathrm{t}_{1} / \mathrm{t}_{0}\right)_{\mathrm{o}}=0.1,\left(\mathrm{~L}_{1} / \mathrm{L}_{0}\right)_{2 \mathrm{o}}=8.8 \text { and }\left(\theta_{\max }\right)_{2 \mathrm{~m}}=0.5429 .(\mathrm{c}) \phi=0.3, \psi=1, \lambda=0.5, \mathrm{k}_{\mathrm{p}}=200, \\
\left(\mathrm{t}_{1} / \mathrm{t}_{0}\right)_{\mathrm{o}}=0.1,\left(\mathrm{~L}_{1} / \mathrm{L}_{0}\right)_{2 \mathrm{o}}=12.3 \text { and }\left(\theta_{\max }\right)_{2 \mathrm{~m}}=0.4329 .(\mathrm{d}) \phi=1, \psi=1, \lambda=0.5, \mathrm{k}_{\mathrm{p}}=200, \\
\left(\mathrm{t}_{1} / \mathrm{t}_{0}\right)_{\mathrm{o}}=0.1,\left(\mathrm{~L}_{1} / \mathrm{L}_{0}\right)_{2 \mathrm{o}}=27.4 \text { and }\left(\theta_{\max }\right)_{2 \mathrm{~m}}=0.3108 .
\end{gathered}
$$




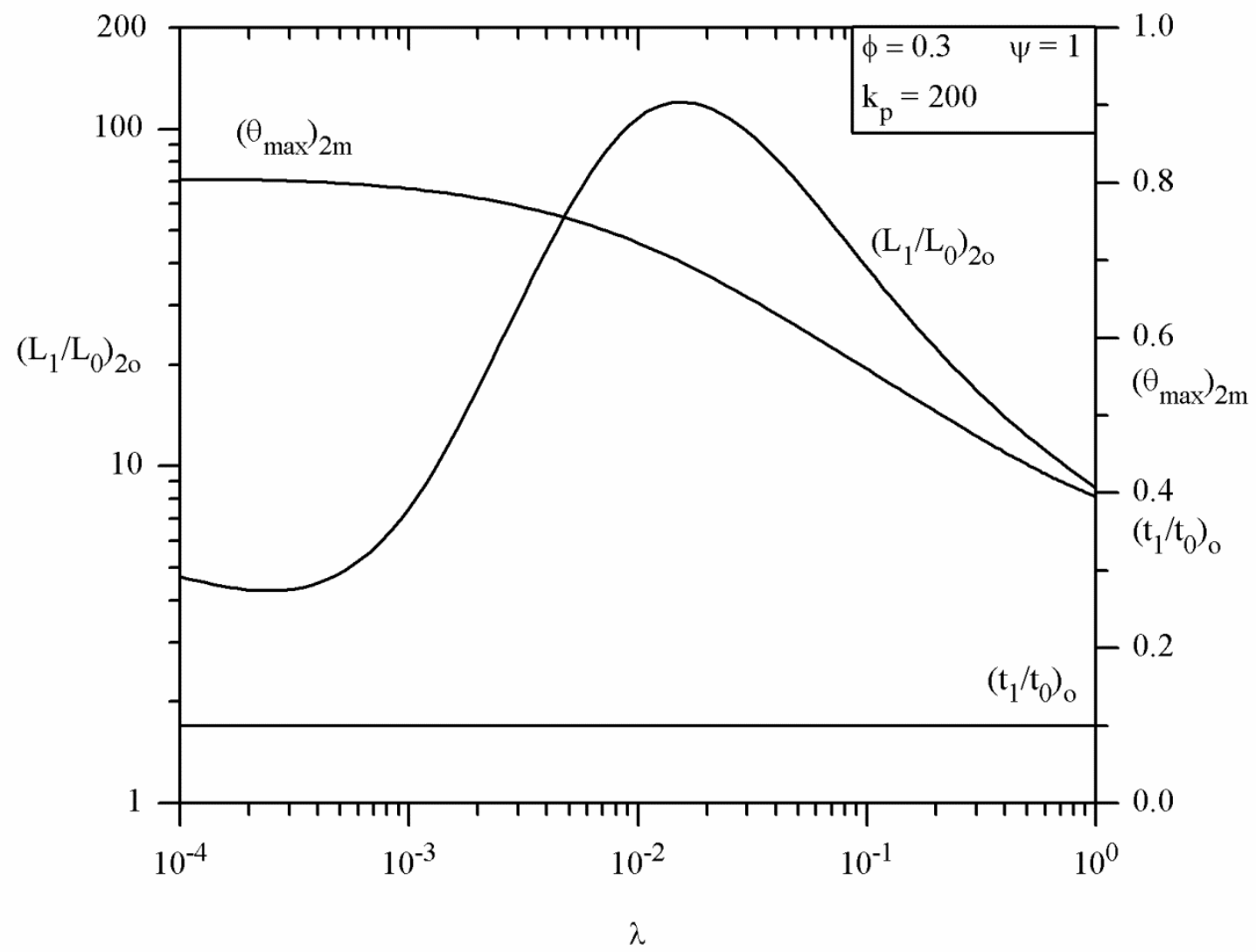

Figure 9 - The twice minimized maximum excess of temperature $\left(\theta_{\max }\right)_{2 \mathrm{~m}}$ and the corresponding optimal shapes $\left(\mathrm{L}_{1} / \mathrm{L}_{0}\right)_{2 o}$ and $\left(\mathrm{t}_{1} / \mathrm{t}_{0}\right)_{\mathrm{o}}$ as a function of the parameter $\lambda$. 


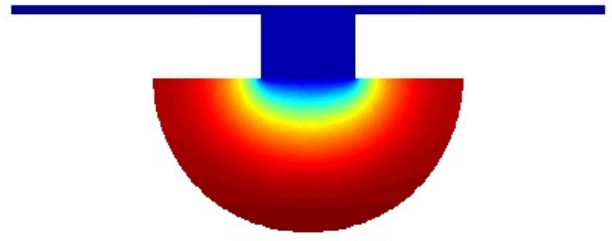

(a)

$$
\begin{gathered}
\phi=0.3 \quad \psi=1.0 \\
\lambda=10^{-4} \quad \mathrm{k}_{\mathrm{p}}=200 \\
\left(\mathrm{t}_{1} / \mathrm{t}_{\mathrm{0}}\right)_{\mathrm{o}}=0.1 \\
\left(\mathrm{~L}_{1} / \mathrm{L}_{0}\right)_{2 \mathrm{o}}=4.7 \\
\left(\theta_{\max }\right)_{2 \mathrm{~m}}=0.8045
\end{gathered}
$$

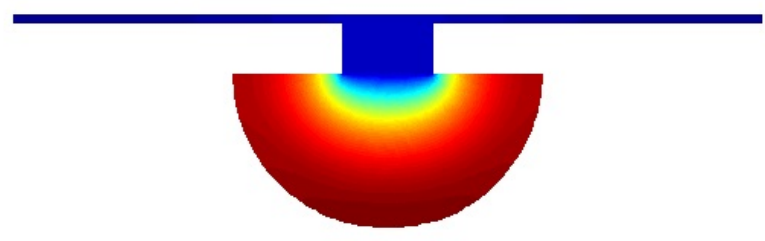

(b)

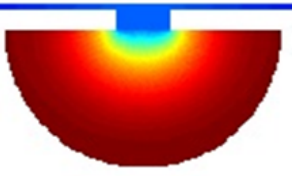

(c)

$$
\begin{gathered}
\phi=0.3 \quad \psi=1.0 \\
\lambda=0.1 \quad \mathrm{k}_{\mathrm{p}}=200 \\
\left(\mathrm{t}_{1} / \mathrm{t}_{0}\right)_{\mathrm{o}}=0.1 \\
\left(\mathrm{~L}_{1} / \mathrm{L}_{0}\right)_{2 \mathrm{o}}=38.7 \\
\left(\theta_{\max }\right)_{2 \mathrm{~m}}=0.5591
\end{gathered}
$$

$$
\begin{gathered}
\phi=0.3 \quad \psi=1.0 \\
\lambda=10^{-3} \quad \mathrm{k}_{\mathrm{p}}=200 \\
\left(\mathrm{t}_{1} / \mathrm{t}_{0}\right)_{\mathrm{o}}=0.1 \\
\left(\mathrm{~L}_{1} / \mathrm{L}_{0}\right)_{2 \mathrm{o}}=7.5 \\
\left(\theta_{\max }\right)_{2 \mathrm{~m}}=0.8016
\end{gathered}
$$

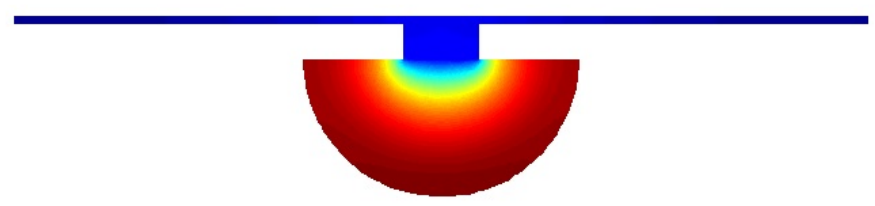

(d)

$$
\begin{gathered}
\phi=0.3 \quad \psi=1.0 \\
\lambda=0.5 \quad \mathrm{k}_{\mathrm{p}}=200 \\
\left(\mathrm{t}_{1} / \mathrm{t}_{\mathrm{0}}\right)_{\mathrm{o}}=0.1 \\
\left(\mathrm{~L}_{1} / \mathrm{L}_{0}\right)_{2 \mathrm{o}}=12.3 \\
\left(\theta_{\text {max }}\right)_{2_{\mathrm{m}}}=0.4329
\end{gathered}
$$

Figure 10 - The shapes of Fig. 9 as function of $\lambda$. (a) $\phi=0.3, \psi=1, \lambda=10^{-4}, \mathrm{k}_{\mathrm{p}}=200$,

$$
\begin{gathered}
\left(\mathrm{t}_{1} / \mathrm{t}_{0}\right)_{\mathrm{o}}=0.1,\left(\mathrm{~L}_{1} / \mathrm{L}_{0}\right)_{2 \mathrm{o}}=4.7 \text { and }\left(\theta_{\max }\right)_{2 \mathrm{~m}}=0.8045 .(\mathrm{b}) \phi=0.3, \psi=1, \lambda=10^{-3}, \mathrm{k}_{\mathrm{p}}=200 \\
\left(\mathrm{t}_{1} / \mathrm{t}_{0}\right)_{\mathrm{o}}=0.1,\left(\mathrm{~L}_{1} / \mathrm{L}_{0}\right)_{2 \mathrm{o}}=7.5 \text { and }\left(\theta_{\max }\right)_{2 \mathrm{~m}}=0.8016 .(\mathrm{c}) \phi=0.3, \psi=1, \lambda=0.1, \mathrm{k}_{\mathrm{p}}=200 \\
\left(\mathrm{t}_{1} / \mathrm{t}_{0}\right)_{\mathrm{o}}=0.1,\left(\mathrm{~L}_{1} / \mathrm{L}_{0}\right)_{2 \mathrm{o}}=38.7 \text { and }\left(\theta_{\max }\right)_{2 \mathrm{~m}}=0.5591 .(\mathrm{d}) \phi=0.3, \psi=1, \lambda=0.5, \mathrm{k}_{\mathrm{p}}=200 \\
\left(\mathrm{t}_{1} / \mathrm{t}_{0}\right)_{\mathrm{o}}=0.1,\left(\mathrm{~L}_{1} / \mathrm{L}_{0}\right)_{2 \mathrm{o}}=12.3 \text { and }\left(\theta_{\max }\right)_{2 \mathrm{~m}}=0.4329 .
\end{gathered}
$$




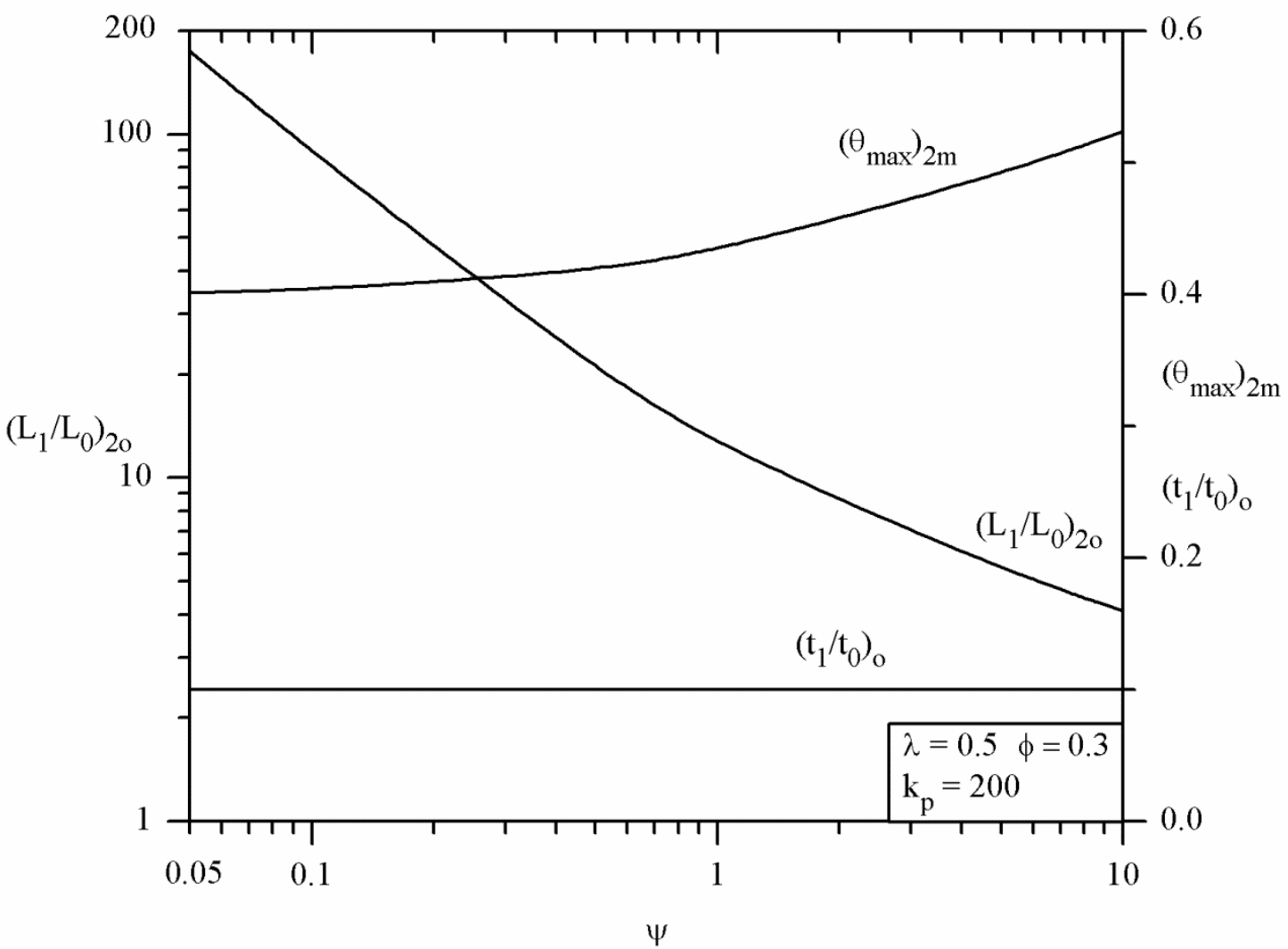

Figure 11 - The effect of the T-shaped fin auxiliary area fraction $\psi$ over the twice minimized maximum excess of temperature $\left(\theta_{\max }\right)_{2 \mathrm{~m}}$ and the corresponding optimal shapes $\left(\mathrm{L}_{1} / \mathrm{L}_{0}\right)_{2 o}$ and $\left(\mathrm{t}_{1} / \mathrm{t}_{0}\right)_{\mathrm{o}}$. 


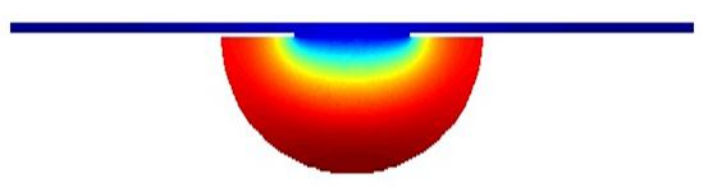

(a)

$$
\begin{gathered}
\phi=0.3 \quad \psi=0.05 \\
\lambda=0.5 \quad \mathrm{k}_{\mathrm{p}}=200 \\
\left(\mathrm{t}_{1} / \mathrm{t}_{0}\right)_{\mathrm{o}}=0.1 \\
\left(\mathrm{~L}_{1} / \mathrm{L}_{0}\right)_{2 \mathrm{o}}=174.6 \\
\left(\theta_{\max }\right)_{2 \mathrm{~m}}=0.4011
\end{gathered}
$$

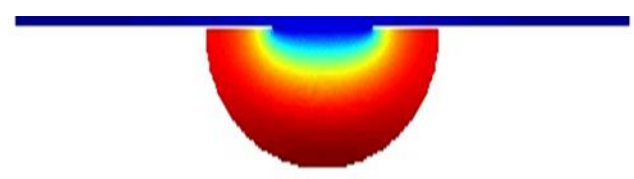

(b)

$$
\phi=0.3 \quad \psi=0.10
$$$$
\lambda=0.5 \quad \mathrm{k}_{\mathrm{p}}=200
$$$$
\left(\mathrm{t}_{1} / \mathrm{t}_{0}\right)_{\mathrm{o}}=0.1
$$$$
\left(\mathrm{L}_{1} / \mathrm{L}_{0}\right)_{2 \mathrm{o}}=88.6
$$

$\left(\theta_{\max }\right)_{2 \mathrm{~m}}=0.4032$

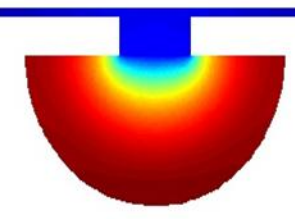

(c)

$$
\begin{array}{cc}
\phi=0.3 & \psi=1.00 \\
\lambda=0.5 & \mathrm{k}_{\mathrm{p}}=200 \\
\left(\mathrm{t}_{1} / \mathrm{t}_{0}\right)_{\mathrm{o}}=0.1 \\
\left(\mathrm{~L}_{1} / \mathrm{L}_{0}\right)_{2 \mathrm{o}}=12.3 \\
\left(\theta_{\max }\right)_{2 \mathrm{~m}}=0.4329
\end{array}
$$

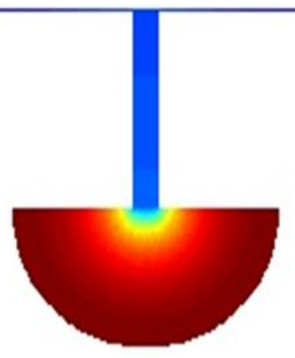

(d)

$$
\begin{gathered}
\phi=0.3 \quad \psi=10.00 \\
\lambda=0.5 \quad \mathrm{k}_{\mathrm{p}}=200 \\
\left(\mathrm{t}_{1} / \mathrm{t}_{0}\right)_{\mathrm{o}}=0.1 \\
\left(\mathrm{~L}_{1} / \mathrm{L}_{0}\right)_{2 \mathrm{o}}=4.1 \\
\left(\theta_{\max }\right)_{2 \mathrm{~m}}=0.5240
\end{gathered}
$$

Figure 12 - The shapes of Fig. 11 as function of $\psi$. (a) $\phi=0.3, \psi=0.05, \lambda=0.5, \mathrm{k}_{\mathrm{p}}=200$,

$$
\begin{gathered}
\left(\mathrm{t}_{1} / \mathrm{t}_{0}\right)_{\mathrm{o}}=0.1,\left(\mathrm{~L}_{1} / \mathrm{L}_{0}\right)_{2 \mathrm{o}}=174.6 \text { and }\left(\theta_{\max }\right)_{2 \mathrm{~m}}=0.4011 .(\mathrm{b}) \phi=0.3, \psi=0.1, \lambda=0.5, \mathrm{k}_{\mathrm{p}}=200 \\
\left(\mathrm{t}_{1} / \mathrm{t}_{0}\right)_{\mathrm{o}}=0.1,\left(\mathrm{~L}_{1} / \mathrm{L}_{0}\right)_{2 \mathrm{o}}=88.6 \text { and }\left(\theta_{\max }\right)_{2 \mathrm{~m}}=0.4032 .(\mathrm{c}) \phi=0.3, \psi=1, \lambda=0.5, \mathrm{k}_{\mathrm{p}}=200 \\
\left(\mathrm{t}_{1} / \mathrm{t}_{0}\right)_{\mathrm{o}}=0.1,\left(\mathrm{~L}_{1} / \mathrm{L}_{0}\right)_{2 \mathrm{o}}=12.3 \text { and }\left(\theta_{\max }\right)_{2 \mathrm{~m}}=0.4329 .(\mathrm{d}) \phi=0.3, \psi=10, \lambda=0.5, \mathrm{k}_{\mathrm{p}}=200 \\
\left(\mathrm{t}_{1} / \mathrm{t}_{0}\right)_{\mathrm{o}}=0.1,\left(\mathrm{~L}_{1} / \mathrm{L}_{0}\right)_{2 \mathrm{o}}=4.1 \text { and }\left(\theta_{\max }\right)_{2 \mathrm{~m}}=0.5240 .
\end{gathered}
$$




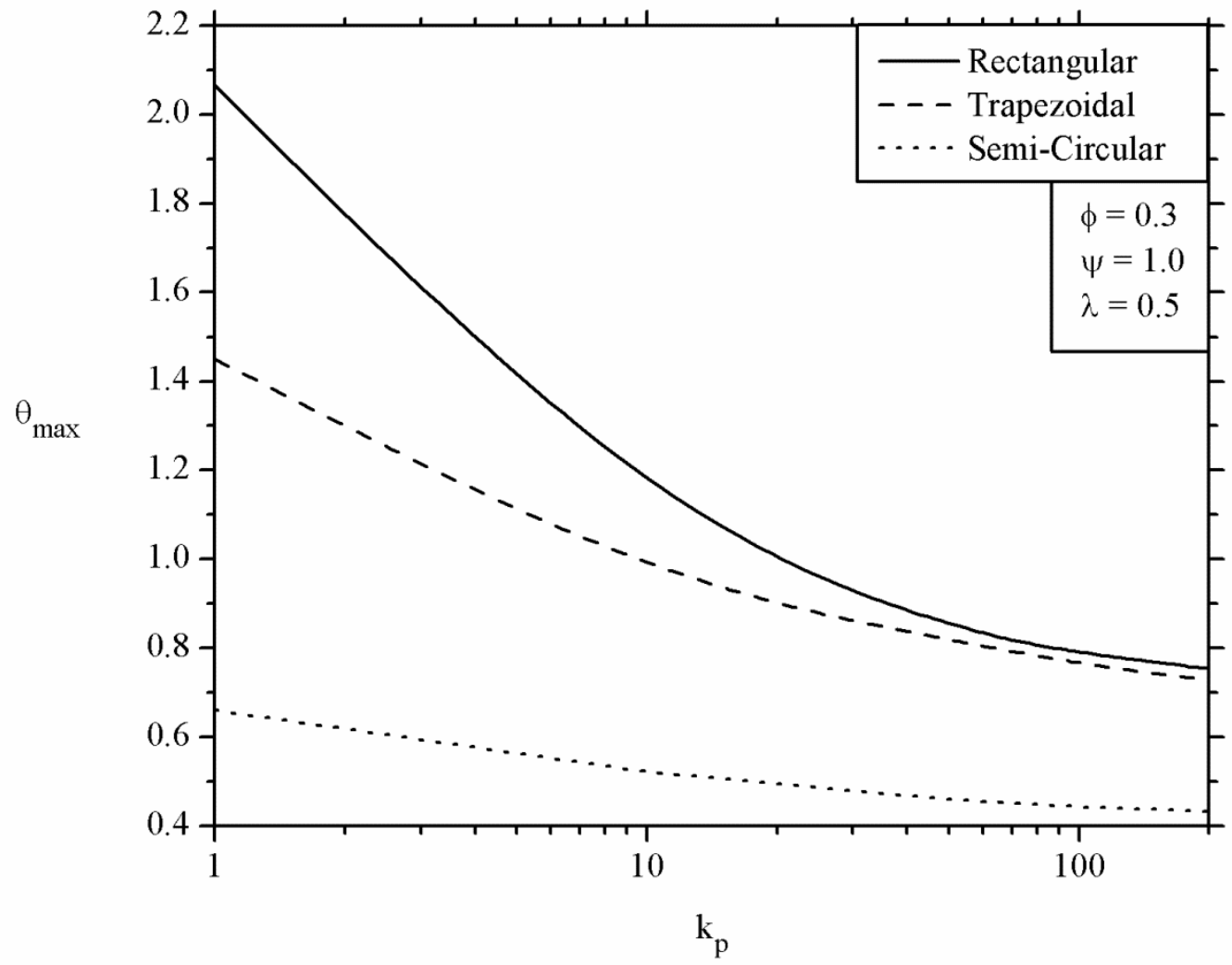

Figure 13 (a) - Comparative analysis between rectangular, trapezoidal and semicircular heat generating body coupled with the same T-shaped fins: the effect of the parameter $k_{p}$ over the maximum excess of temperature $\theta_{\max }$. 


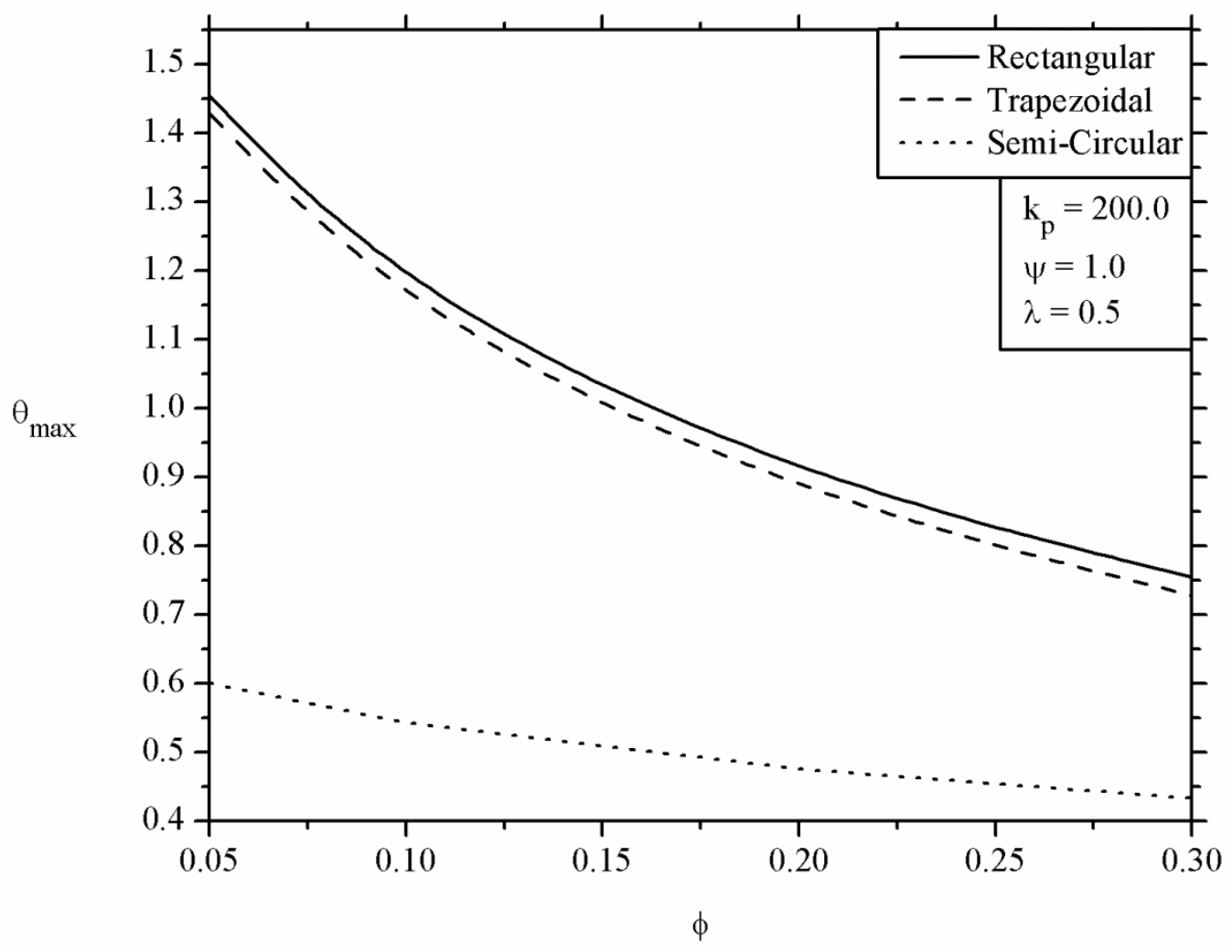

Figure 13 (b) - Comparative analysis between rectangular, trapezoidal and semicircular heat generating body coupled with the same T-shaped fins: the effect of the area fraction $\phi$ over the maximum excess of temperature $\theta_{\max }$. 


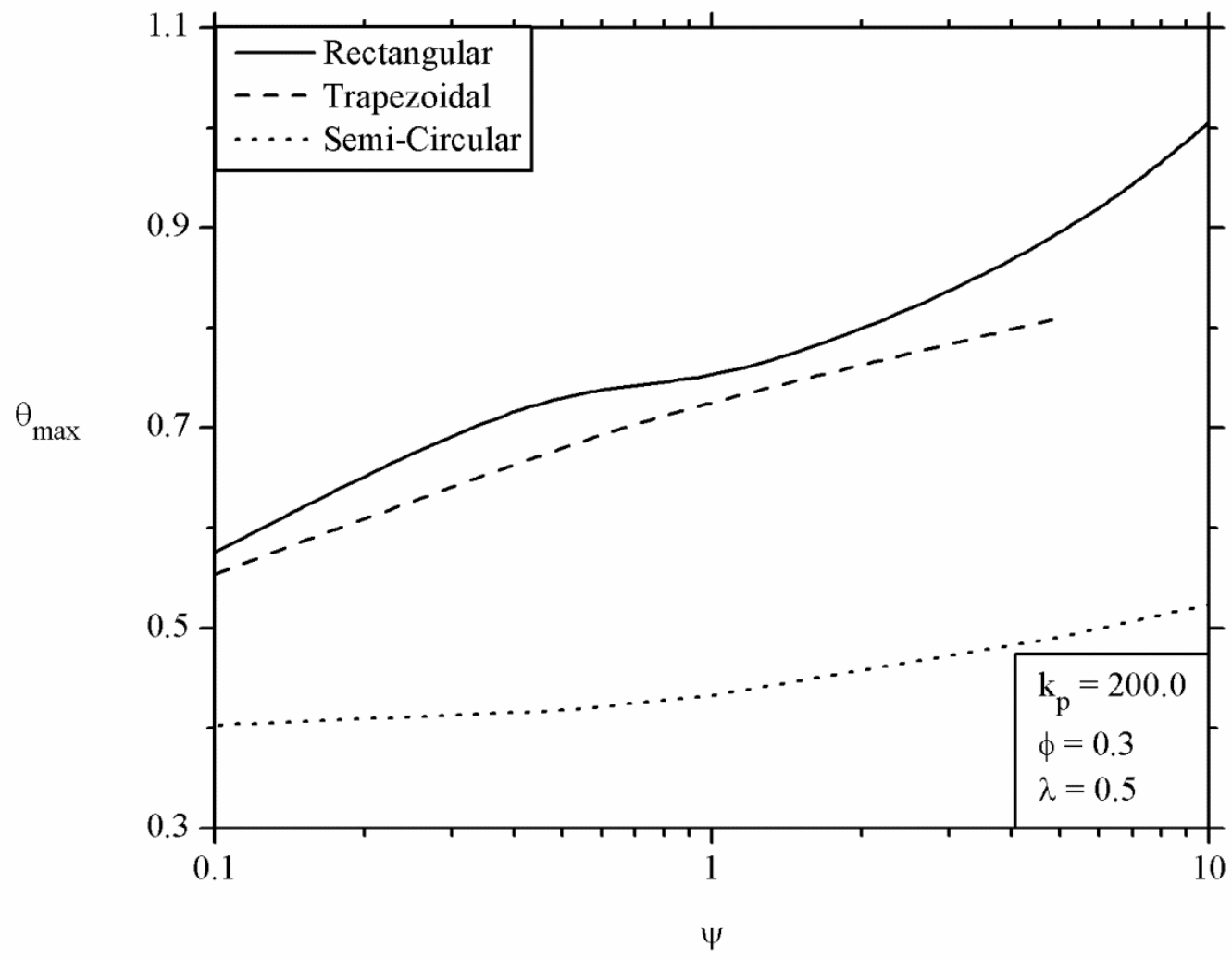

Figure 13 (c) - Comparative analysis between rectangular, trapezoidal and semicircular heat generating body coupled with the same T-shaped fins: the effect of the auxiliary area fraction $\psi$ over the maximum excess of temperature $\theta_{\text {max }}$. 


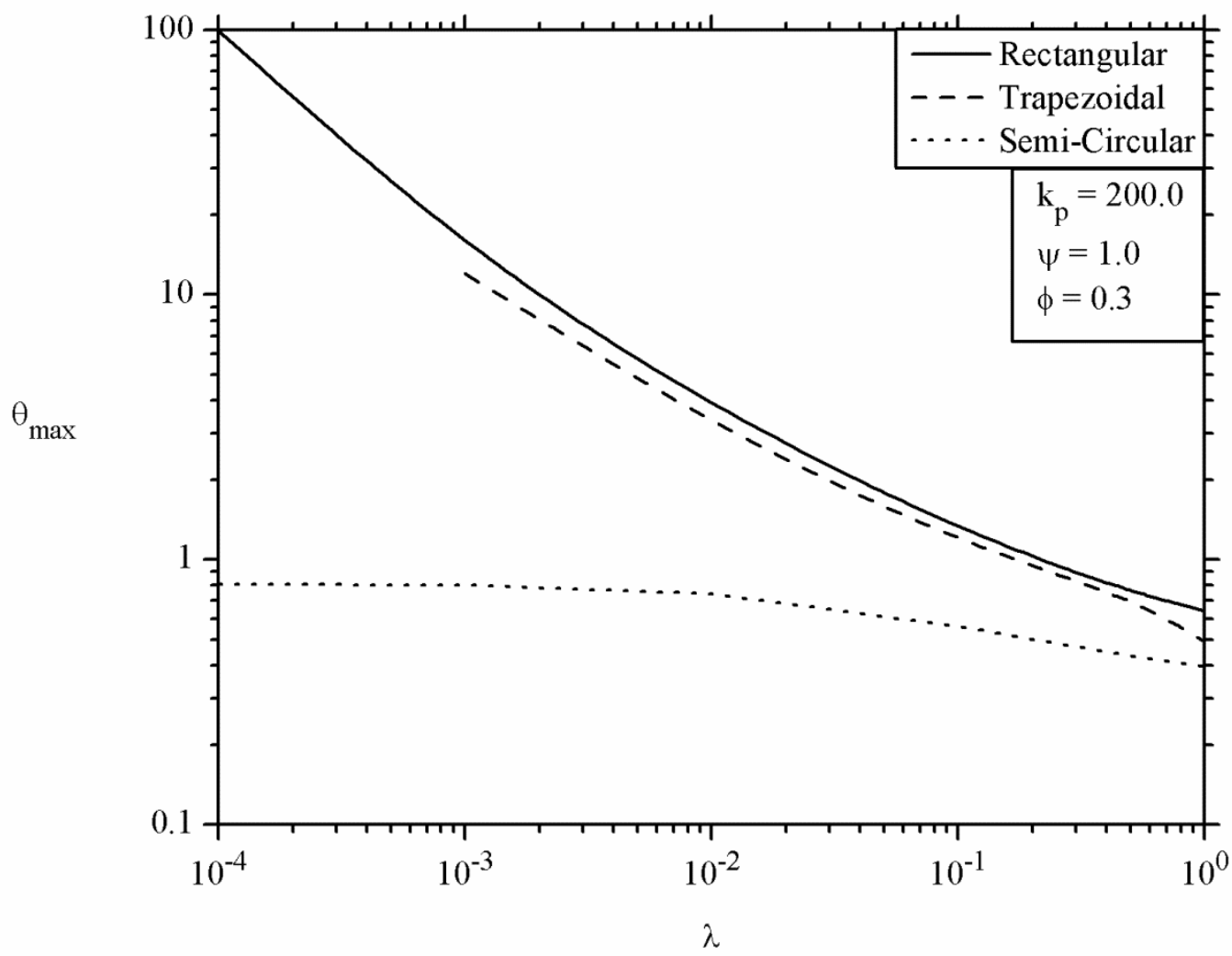

Figure 13 (d) - Comparative analysis between rectangular, trapezoidal and semicircular heat generating body coupled with the same T-shaped fins: the effect of the parameter $\lambda$ over the maximum excess of temperature $\theta_{\max }$. 